\title{
Dynamic Complexity in the Electrochemical Oxidation of Thiourea
}

\author{
Jiamin Feng, ${ }^{\dagger}$ Qingyu Gao, ${ }^{\dagger, \ddagger}$ Xiaoli Lv,${ }^{\dagger}$ and Irving R. Epstein*, \\ College of Chemical Engineering, China University of Mining and Technology, Xuzhou 221008, \\ People's Republic of China, and Department of Chemistry and Volen Center for Complex Systems, \\ MS 015, Brandeis University, Waltham, Massachusetts 02454-9110
}

Received: March 6, 2008; Revised Manuscript Received: April 16, 2008

\begin{abstract}
We explored the temperature-dependent dynamics of the electrochemical oxidation of thiourea under potentialcontrol mode and found complex oscillations with one large peak and one small peak per period. Adjusting the temperature caused the relative amplitudes and positions of the two peaks to vary. Experiments showed that there were two distinct oscillatory regimes as a function of the external current, and at some temperatures, three-frequency quasiperiodic oscillations occurred for current densities between the two oscillatory windows. We examined the species present and the component reactions by employing cyclic voltammetry and electrolysis-HPLC-MS in the two oscillatory regimes. Adsorption and desorption of multiple species, including water and chloride, contribute to the rich dynamical phenomena that were observed.
\end{abstract}

\section{Introduction}

Among the wealth of phenomena displayed by nonlinear systems maintained far from thermodynamic equilibrium, ${ }^{1-4}$ perhaps the most remarkable are deterministic chaos and the scenarios by which it evolves from simple oscillations. These "universal" behaviors appear in a variety of systems in physics, engineering, biology, chemistry, and electrochemistry. ${ }^{5-14}$ The effort to understand chaos has attracted a great deal of attention in the past four decades. When a parameter of a deterministic system is varied, chaotic behavior can appear through a number of routes, including period-doubling, quasiperiodic, mixed-mode, and intermittent bifurcations. ${ }^{1}$ In these scenarios, the system first undergoes a Hopf bifurcation, which generates a stable limit cycle from a steady state. As the control parameter is further varied, an additional fundamental frequency can arise, causing more complex oscillations. Landau and Dokl ${ }^{15}$ suggested one route to chaos, through an infinite sequence of Hopf bifurcations, to explain the generation of turbulence in fluid systems. Ruelle and co-workers ${ }^{16,17}$ proposed that chaos could be obtained after three bifurcations with the generation of only two incommensurate frequencies, where arbitrarily small changes convert the system from quasiperiodic to chaotic. This scenario was later observed in experiments on Rayleigh-Bénard convection. ${ }^{4,18}$

It might be expected that three-frequency quasiperiodic oscillations would be difficult to observe, given that they can be destroyed by small perturbations. Indeed, an oft-quoted article proclaims that "Period three implies chaos." 19 Grebogi, Ott, and Yorke ${ }^{20}$ showed numerically, however, that addition of a smooth nonlinear perturbation does not necessarily generate a chaotic attractor. Yet, three-frequency quasiperiodicity in experiments remains a rare phenomenon. Examples include a Rayleigh-Bénard experiment with mercury in a magnetic field by Libchaber et al. ${ }^{21}$ and the voltage spectrum of a ferroelectric barium sodium niobate (BSN) crystal observed by Martin et al. ${ }^{22}$ To our knowledge, no previous observation of such behavior in chemical or electrochemical systems has been reported.

* To whom correspondence should be addressed. E-mail: epstein@ brandeis.edu.

$\dagger$ China University of Mining and Technology.

$¥$ Brandeis University.
Initial studies of the electrochemical oxidation of thiourea revealed that the reaction is a complex process, and several possible products were suggested. ${ }^{23,24}$ However, the mechanism remains obscure, and further studies are clearly needed. Recently, we reported that the electrochemical oxidation of thiourea in the presence of adsorbed chloride ion displays a period-doubling bifurcation and other complex oscillations under potentiostatic conditions. ${ }^{25}$ Here, we show that the same system is capable of exhibiting more complex dynamical behaviors, including temperature-dependent mixed-mode oscillations under potential-control mode and two- and three-frequency quasiperiodic oscillations under galvanostatic conditions. In addition to probing the system dynamics, we carried out a detailed investigation of the relevant species and electrochemical reactions by combining cyclic voltammetry $(\mathrm{CV})$ with electrolysis-highperformance liquid chromatography (HPLC) - mass spectrometry (MS). We were able to detect several oxidation products directly, and we propose a mechanism for this electrochemical process.

\section{Experimental Section}

Cyclic voltammetry, linear galvanic voltammetry, and all dynamic electrochemical measurements were conducted in a cylindrical cell with an internal diameter of $5.5 \mathrm{~cm}$ and a volume of $40 \mathrm{~mL}$. The working electrode was a polycrystalline platinum disk with a diameter of $2.0 \mathrm{~mm}$ (CH Instruments, Austin, TX), and the counter electrode was a platinum wire. The reference electrode, a saturated calomel electrode (SCE), was linked to the cell through a salt bridge. The three electrodes formed an equilateral triangle, $1.8 \mathrm{~cm}$ on a side. Before each experiment, the working electrode was first polished with fine alumina powder $(0.05 \mu \mathrm{m})$ and then immersed in a $1: 1 \mathrm{v} / \mathrm{v}$ mixture of $\mathrm{HNO}_{3}(60 \%)$ and $\mathrm{H}_{2} \mathrm{O}_{2}(30 \%)$ at $60{ }^{\circ} \mathrm{C}$ for $30 \mathrm{~min}$. After that, cyclic potential sweeps between -0.25 and $1.2 \mathrm{~V}$ at a scan rate of $1.0 \mathrm{~V} / \mathrm{s}$ were performed in $0.5 \mathrm{M} \mathrm{H}_{2} \mathrm{SO}_{4}$ solution for $30 \mathrm{~min}$ to further clean the electrode surface. The Pt electrode was rinsed repeatedly with Milli-Q water and transferred to the test solution under the protection of a water droplet on its surface.

Potentiostatic electrolysis experiments for HPLC analysis were performed in a glass cell with a volume of $2.5 \mathrm{~mL}$ 

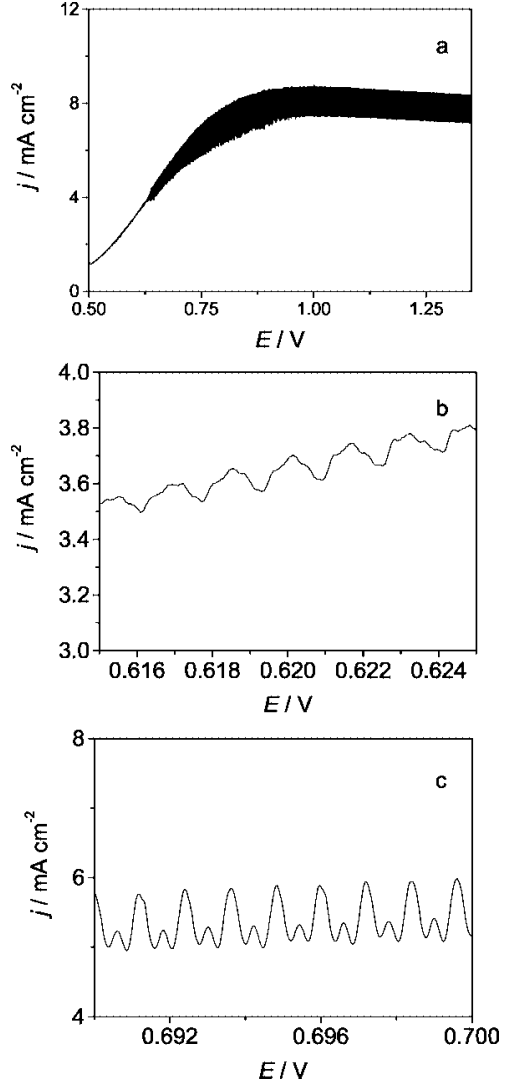

Figure 1. (a) Linear sweep voltammogram of thiourea on a platinum electrode at $0.01 \mathrm{mV} / \mathrm{s}$ and $(\mathrm{b}, \mathrm{c})$ enlargements showing the transition from simple to multimode oscillations. Electrolyte solution: $0.2 \mathrm{M}$ thiourea, $0.3 \mathrm{M} \mathrm{KCl}, 2.18 \mathrm{M} \mathrm{HCl}$. Temperature: $5{ }^{\circ} \mathrm{C}$.

equipped with a magnetic stirrer. Both the working and counter electrodes were platinum wires, and an SCE was used as the reference electrode. High-performance liquid chromatography experiments were performed on an Agilent 1100 system equipped with a quaternary pump and an MWD UV detector (Agilent, Santa Clara, CA). Separation was achieved on a Phenomenex Ginimi $\mathrm{C}_{18}$ column $(5 \mu \mathrm{m}, 250 \times 4.6 \mathrm{~mm}$ i.d. $)$ at $25^{\circ} \mathrm{C}$. The mobile-phase composition was methanol/acetonitrile/ water $(\mathrm{HCl}, \mathrm{pH}=2)=6: 26: 68(\mathrm{v} / \mathrm{v} / \mathrm{v})$, and the flow rate was $0.4 \mathrm{~mL} / \mathrm{min}$. Before each injection, the solution was diluted 5-fold, and a wavelength of $214 \mathrm{~nm}$ was selected for data recording. In the HPLC-MS experiments, the LC column effluent was interfaced with an LCQ Advantage ion-trap mass spectrometer (Thermo Finnigan, Waltham, MA) equipped with an electrospray ionization (ESI) ion source. Both positive- and negative-ion modes were used to detect different substances. The sheath and auxiliary/sweep gas flow rates were set to 30 and 10 arbitrary unit, respectively, and the capillary temperature was $300{ }^{\circ} \mathrm{C}$. The probe voltage was kept at $+3.0 \mathrm{kV}$ in positiveion mode and $-2.0 \mathrm{kV}$ in negative-ion mode.

All electrochemical experiments were performed on a $\mathrm{CHI}$ 660A Electrochemical Workstation ( $\mathrm{CH}$ Instruments). Water used in all experiments was purified with a Millipore Milli-Q system $(18.2 \mathrm{M} \Omega \cdot \mathrm{cm})$. The methanol and acetonitrile used in this work were HPLC grade, and all other chemicals were analytical grade. Before each experiment, oxygen was removed from the solution by bubbling with ultrapure (>99.9\%) nitrogen.

\section{Results and Discussion}

a. Potential Control. Figure 1 presents a linear voltammogram of thiourea on a platinum electrode at a scan rate of 0.01
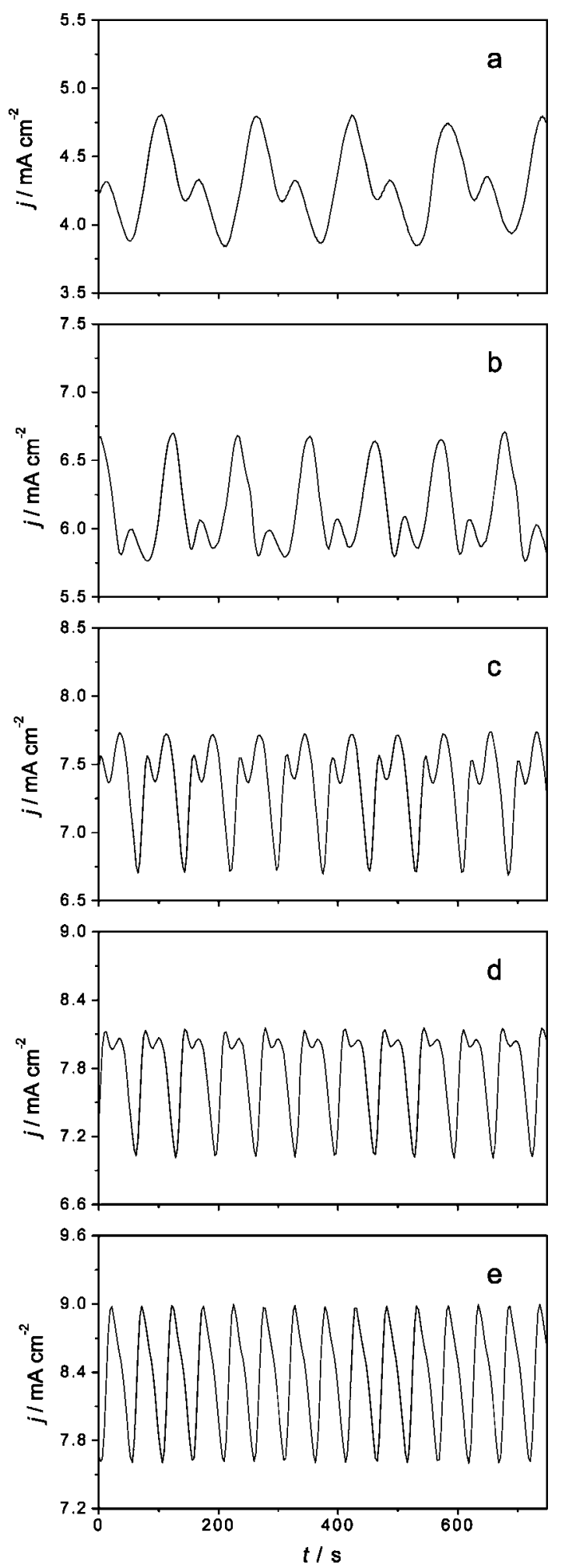

Figure 2. Current oscillations obtained at (a) -1.5 , (b) 1 , (c) 7 , (d) 9 , and (e) $12{ }^{\circ} \mathrm{C}$. The applied potential was $0.75 \mathrm{~V}$, and the other conditions were as in Figure 1.

$\mathrm{mV} / \mathrm{s}$ at $5{ }^{\circ} \mathrm{C}$. Scanning at such a low rate is analogous to measuring a bifurcation diagram with the applied potential as the control parameter. The system moves through the various dynamical regimes, and the bifurcation behavior can be observed on the voltammogram. As shown in Figure 1a, when the applied potential approaches ca. $0.6 \mathrm{~V}$, fluctuations in current begin, and the amplitude of the current oscillations increases smoothly and quadratically with the applied potential, indicating that the 

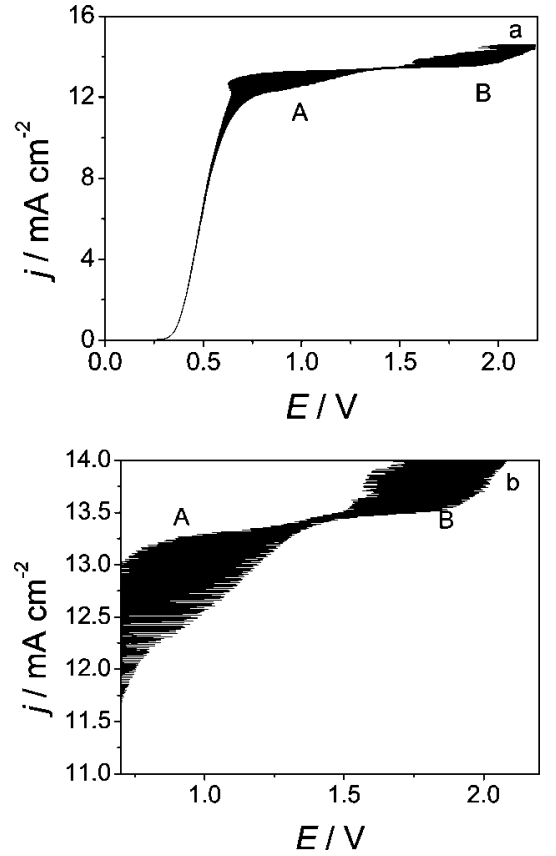

Figure 3. (a) Linear galvanic scan at $0.01 \mathrm{~mA} / \mathrm{s}$. Composition: $0.2 \mathrm{M}$ thiourea, $0.3 \mathrm{M} \mathrm{KCl}, 1.5 \mathrm{M} \mathrm{HCl}$. Temperature: $15^{\circ} \mathrm{C}$. (b) Enlargement of the region around transition between $\mathrm{A}$ - and B-type oscillations.

current oscillations arise through a supercritical Hopf bifurcation. As the potential increases to ca. $0.9 \mathrm{~V}$, a plateau appears, and the peak-to-peak amplitude of oscillation reaches its maximum, ca. $3 \mathrm{~mA} / \mathrm{cm}^{2}$. In addition to the changes in amplitude, the waveform of the oscillations evolves from simple periodic to complex as shown in Figure 1b,c.

We showed earlier that the applied potential and the concentration of $\mathrm{HCl}$ can be taken as control parameters that give rise to period-doubling bifurcations and the appearance of complex oscillations. ${ }^{25} \mathrm{We}$ find here, as demonstrated in Figure 2 , that the reaction temperature also has a significant influence on the dynamic behavior. When the oxidation of thiourea is carried out at $0.75 \mathrm{~V}$, complex oscillations (Figure 2a) can be observed at $-1.5{ }^{\circ} \mathrm{C}$. In each period, a large oscillation is followed by a smaller one, which starts at about the half-height of the large peak. The relative amplitudes and phases of the large and small peaks can be modulated by temperature. In Figure $2 b$, for which the temperature was $1{ }^{\circ} \mathrm{C}$, the small oscillation still lies to the right of the large one, but its amplitude is now much smaller. If the temperature is increased further, the small oscillation moves to the left of the larger one, as seen in Figure 2c for a temperature of $7{ }^{\circ} \mathrm{C}$. As we continue to increase the temperature, the scenario of changing relative amplitudes and phases is repeated. Above about $12{ }^{\circ} \mathrm{C}$, this complex behavior gives way to simple, single-peak oscillations, ${ }^{25}$ as shown in Figure 2e.

b. Current Control. Figure 3 shows a linear galvanic voltammogram obtained by slowly sweeping the applied current density at $15^{\circ} \mathrm{C}$. Here, the electrochemical oxidation of thiourea exhibits two distinct oscillatory regimes, labeled $\mathrm{A}$ and $\mathrm{B}$. Oscillation A appears as the current density goes above ca. 1.4 $\mathrm{mA} / \mathrm{cm}^{2}$. The smooth quadratic increase in the amplitude with applied anodic current again suggests a supercritical Hopf bifurcation. When the current density approaches ca. $13.5 \mathrm{~mA} /$ $\mathrm{cm}^{2}$, the oscillation amplitude reaches its maximum. If the current density is increased further, the system undergoes a transition from oscillation A to oscillation B (Figure 3b). Under these conditions, the interval between oscillations $\mathrm{A}$ and $\mathrm{B}$ is
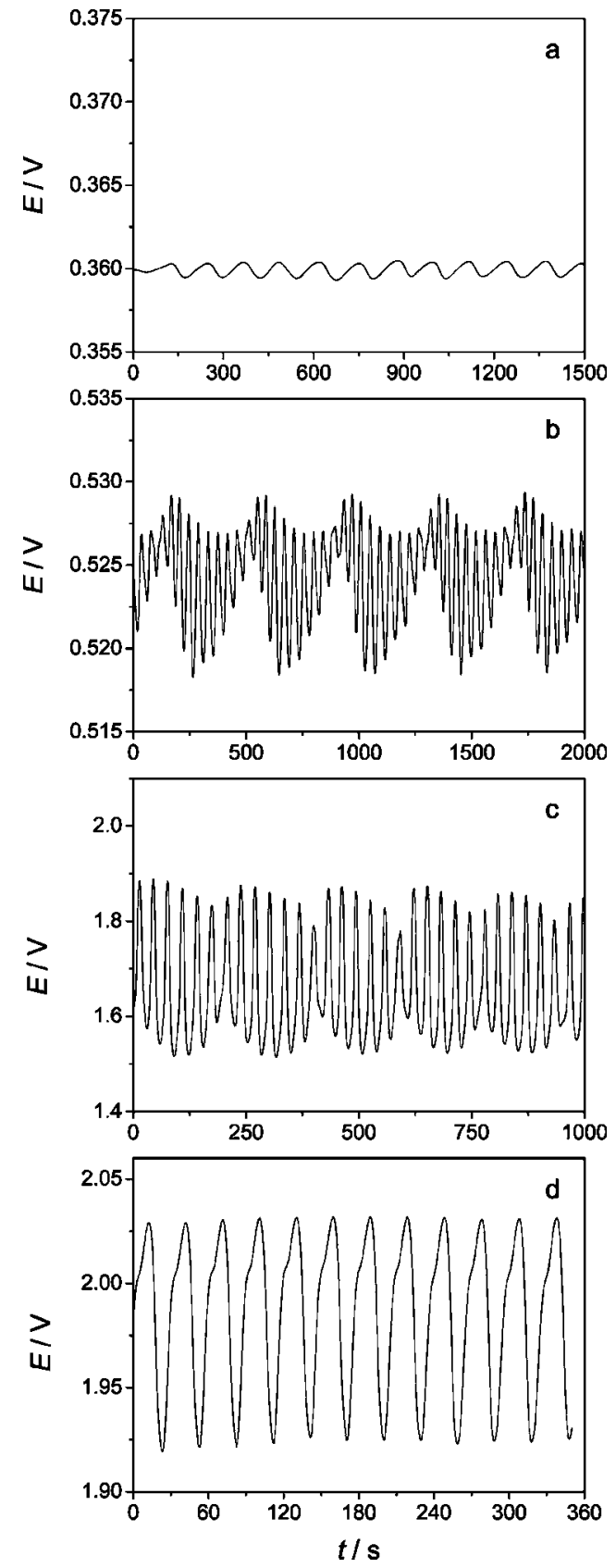

Figure 4. Potential oscillations at different current densities: (a) 1.60 , (b) 4.77 , (c) 10.50 , and (d) $12.41 \mathrm{~mA} / \mathrm{cm}^{2}$. Other conditions as in Figure 3.

quite small, and the two regions nearly overlap, which explains why a single continuous oscillatory regime is observed under potentiostatic sweep conditions at some temperatures.

To fully characterize the dynamical properties in constantcurrent mode, we performed galvanostatic chronopotentiometry for long time periods. Figure 4 shows potential oscillations obtained at $15^{\circ} \mathrm{C}$ with all other conditions the same as in Figure 3 . Figure 4 a presents the potential oscillations obtained at 1.60 $\mathrm{mA} / \mathrm{cm}^{2}$, close to the Hopf bifurcation. Only simple oscillations can be observed here, with an amplitude of about $2 \mathrm{mV}$ and a period of about $120 \mathrm{~s}$. As we increase the current density, both the amplitude and the frequency of the oscillations increase, until another incommensurate frequency is generated through a second Hopf bifurcation, producing quasiperiodic oscillations (Figure $4 b$ ). If we increase the current density further, the oscillations shift to more positive potential, and the amplitude 

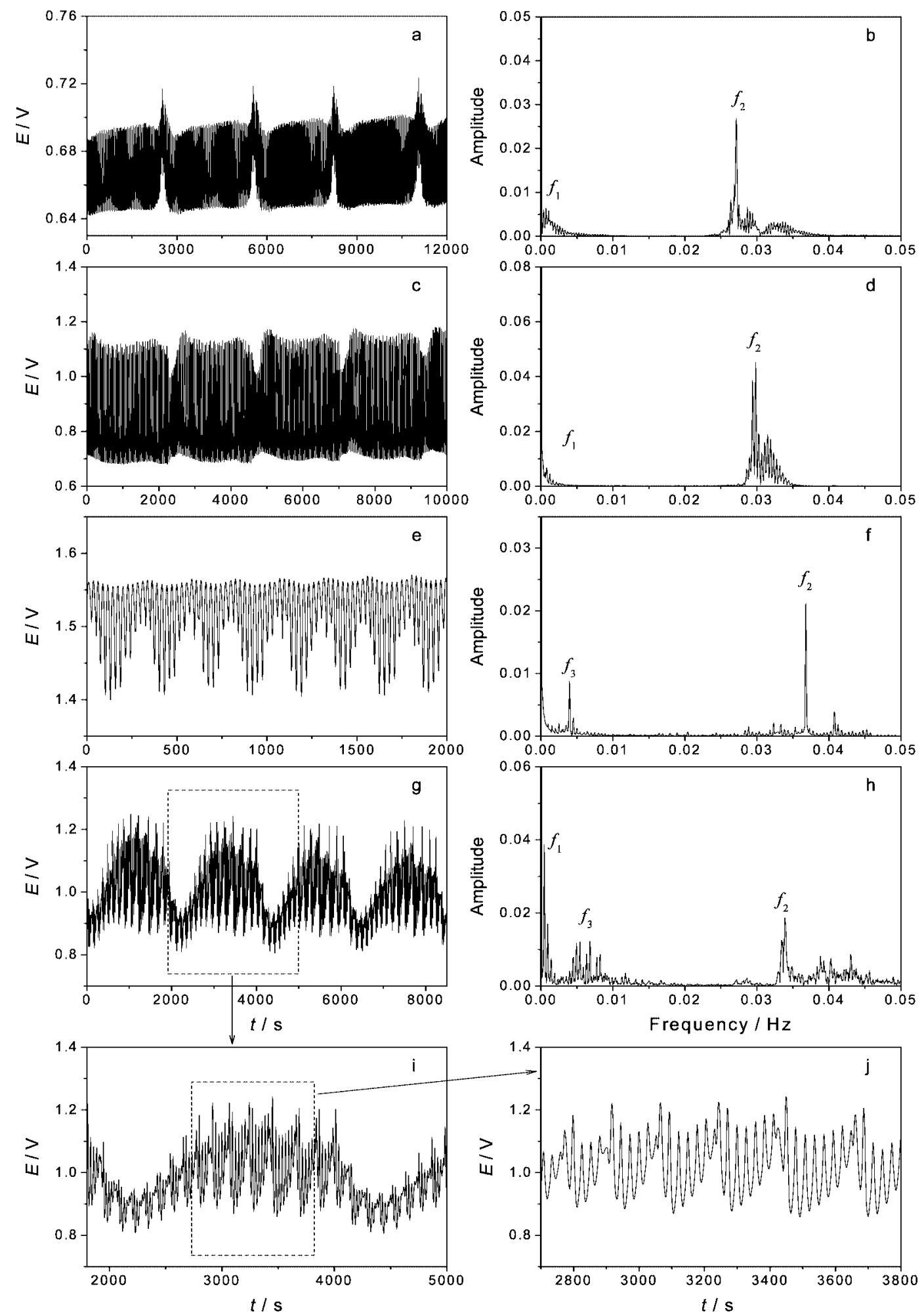

Figure 5. (a,c,e,g,i,j) Potential oscillations and (b,d,f,h) corresponding power spectra at $20{ }^{\circ} \mathrm{C}$ and current densities of (a,b) 10.50 , (c,d) 11.30 , (e,f) 11.78 , and $(\mathrm{g}, \mathrm{h}, \mathrm{i}, \mathrm{j}) 11.35 \mathrm{~mA} / \mathrm{cm}^{2}$.

increases as well, but the quasiperiodic behavior persists. When the current density reaches ca. $10 \mathrm{~mA} / \mathrm{cm}^{2}$, the system lies at the border of oscillation region $\mathrm{A}$, at a current density somewhat lower than the value suggested by the dynamic linear galvanic voltammogram in Figure 3. Here, even a very small increase in current density will drive the system into oscillation B. This jump is accompanied by transient oscillations, as the system, initially in oscillatory region A, oscillates at higher and higher potentials until it reaches oscillatory region $\mathrm{B}$. If the current density is raised still further, stable B-type oscillations are obtained. As shown in Figure 4c, near the boundary, quasiperiodic oscillations are observed. At higher current densities (Figure 4d), simple oscillations are restored.

As in potential-control mode, temperature also has a significant influence on the dynamical behavior under galvanostatic conditions. Figure 5 shows the potential oscillations and the corresponding power spectra observed at $20{ }^{\circ} \mathrm{C}$ for several values of the applied current density. When the current density 

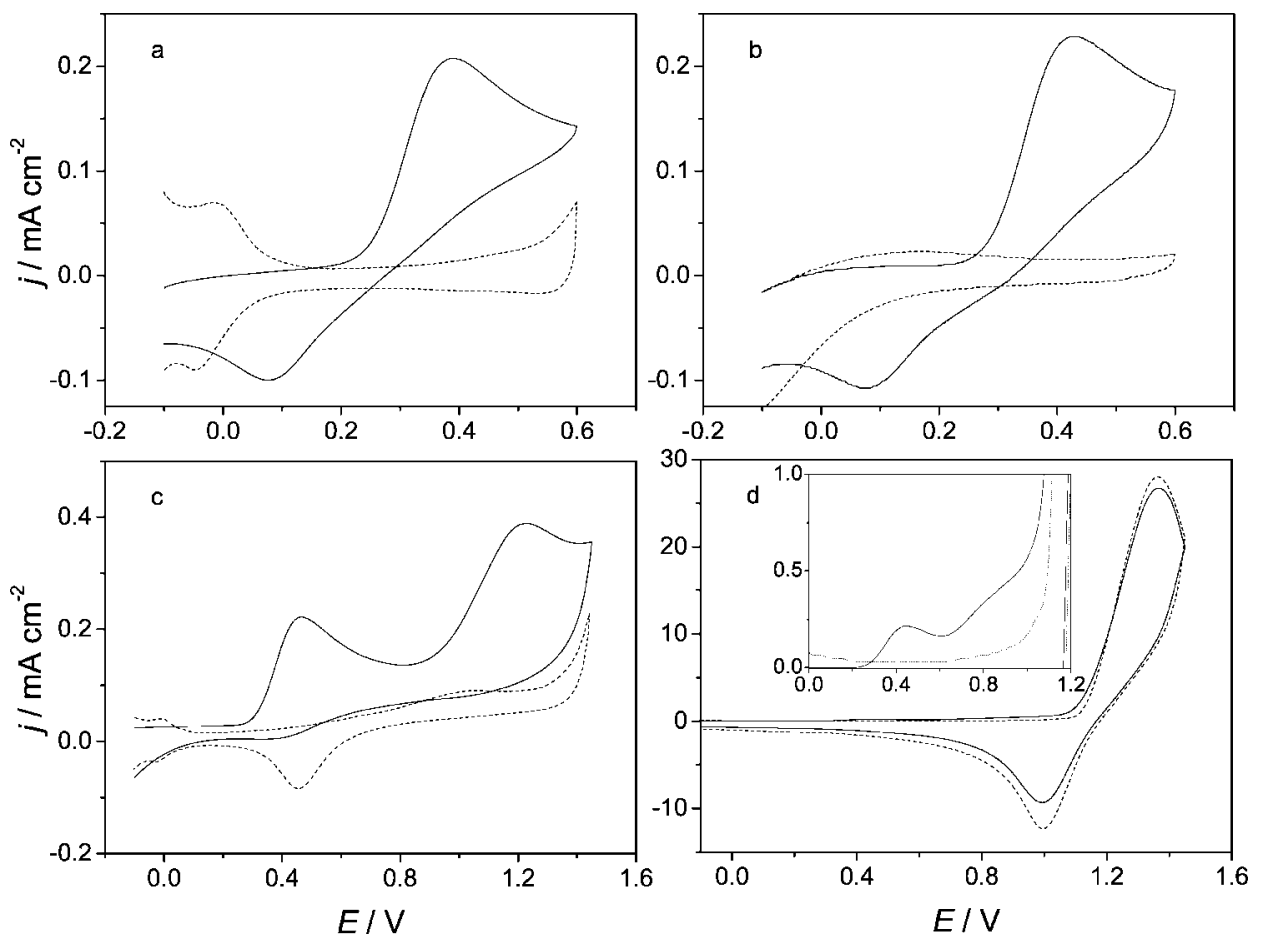

Figure 6. Cyclic voltammograms in (a,c) $0.5 \mathrm{M} \mathrm{HClO}_{4}$ and (b,d) $0.5 \mathrm{M} \mathrm{HCl}$ solutions in the absence (dashed line) and presence (solid line) of 1 $\mathrm{mM}$ thiourea. Scan rate: $0.05 \mathrm{~V} / \mathrm{s}$. Temperature: $25^{\circ} \mathrm{C}$. Potential range: $(\mathrm{a}, \mathrm{b})$ between -0.1 and $0.6 \mathrm{~V}$ and $(\mathrm{c}, \mathrm{d})$ between -0.1 and $1.45 \mathrm{~V}$.

is $10.50 \mathrm{~mA} / \mathrm{cm}^{2}$ (Figure 5a), complex oscillations appear. Although the waveform is quite different from that in Figure $4 \mathrm{~b}$, the quasiperiodic character is still apparent in the power spectrum (Figure $5 b$ ), where two incommensurate frequencies are observed. The first frequency, $f_{1}$, appears at around $0.4 \mathrm{mHz}$, which corresponds to the long-time behavior of the potential. The other frequency, $f_{2}$, at about $0.027 \mathrm{~Hz}$ corresponds to the high-frequency oscillations. When the current density is raised to $11.30 \mathrm{~mA} / \mathrm{cm}^{2}$, the mean potential rises, and the amplitude increases to about $0.4 \mathrm{~V}$. The two-frequency quasiperiodicity persists, and both $f_{1}$ and $f_{2}$ increase. If the current density is further increased, the system undergoes a transition to oscillatory region B. As shown in Figure 5e, at $11.78 \mathrm{~mA} / \mathrm{cm}^{2}, f_{1}$ disappears, and another frequency, $f_{3}$, arises; that is, the system displays a new mode of two-frequency $\left(f_{2}\right.$ and $\left.f_{3}\right)$ oscillation.

If the current density is set in the region between oscillations A and B, e.g., at $11.35 \mathrm{~mA} / \mathrm{cm}^{2}$, the behavior becomes more complex, as seen in Figure 5g. The power spectrum, shown in Figure $5 \mathrm{~h}$, contains three frequencies: $f_{1} \approx 0.57 \mathrm{mHz}, f_{2} \approx 0.034$ $\mathrm{Hz}$, and $f_{3} \approx 5.0 \mathrm{mHz}$. To exhibit the high-frequency oscillations more clearly, we expanded the time scale in Figure 5i,j. These results suggest the presence of a three-frequency quasiperiodic oscillation. To our knowledge, this is the first system with the ability to support a three-frequency torus in either a chemical or an electrochemical system.

As seen in Figure 3, at most temperatures, there are two distinct oscillatory regimes under galvanostatic conditions. From their mean potentials, the oscillations in Figure 5a,c and Figure 5e can be assigned to oscillatory regions $\mathrm{A}$ and $\mathrm{B}$, respectively. At $15{ }^{\circ} \mathrm{C}$, we find two-frequency quasiperiodic oscillations at both the upper border of oscillation $\mathrm{A}$ and the lower border of oscillation B. A similar scenario might be expected at $20^{\circ} \mathrm{C}$, but the three-frequency quasiperiodic orbit in Figure $5 \mathrm{~g}$ arises between the two oscillatory regions. The two oscillatory regimes overlap somewhat, and one of the domain frequencies, $f_{2}$, in the three-frequency oscillation is common to both $\mathrm{A}$ and $\mathrm{B}$, whereas $f_{1}$ and $f_{3}$ can be seen in $\mathrm{A}$ and $\mathrm{B}$, respectively. These observations strongly suggest that this rare phenomenon arises from the interaction between oscillatory modes A and B.

c. Analysis of Species and Electrochemical Reactions. To study the chemical processes that underlie the oscillatory behavior, we also carried out cyclic voltammetry experiments. In order to evaluate the influence of chloride adsorption on the electrochemical oxidation of thiourea, we employed both nonadsorbing $\mathrm{HClO}_{4}$ and $\mathrm{HCl}$ as supporting electrolytes. Figure 6 presents cyclic voltammograms obtained in the absence (dotted line) and presence (solid line) of $1 \mathrm{mM}$ thiourea. With only 0.5 $\mathrm{M} \mathrm{HClO}_{4}$ present, two pairs of current peaks are observed in the potential range between -0.05 and $-0.1 \mathrm{~V}$, corresponding to the adsorption and desorption of hydrogen. Adsorption of oxygen occurs when the potential is above ca. $0.5 \mathrm{~V}$ in the positive scan direction. If the switching potential is increased to $1.45 \mathrm{~V}$, oxygen evolution can be observed at potentials above 1.4 V (dotted line in Figure 6c), and desorption of the oxygen monolayer occurs at ca. $0.5 \mathrm{~V}$ in the reverse scan.

When $1 \mathrm{mM}$ thiourea is added to the $\mathrm{HClO}_{4}$ solution, adsorption and desorption of hydrogen are inhibited almost completely. In the forward scan, oxidation of thiourea occurs when the potential is above ca. $0.2 \mathrm{~V}$. As shown in Figure 6a, a pair of current peaks is obtained at 0.40 and $0.08 \mathrm{~V}$. The difference between the two peak potentials, $320 \mathrm{mV}$, is much larger than that expected for a reversible (Nernstian) system, $58 / n$, where $n$ is the number of electrons transferred in the process. This observation indicates that the oxidation of thiourea at these potentials is sluggish and irreversible. ${ }^{26}$ Further experiments revealed that the anodic peak current in Figure 6a increases linearly with the concentration of thiourea and with the square root of the scan rate. From this relationship, we evaluated the number of electrons transferred as 1 equiv/mol. As seen in Figure 6c, thiourea can be further oxidized at potentials above ca. $0.8 \mathrm{~V}$, where oxygen adsorption is quite facile in the blank solution.

When the experiments are conducted in $0.5 \mathrm{M} \mathrm{HCl}$, as shown in Figure $6 \mathrm{~b}, \mathrm{~d}$, the voltammograms are similar to those in 0.5 


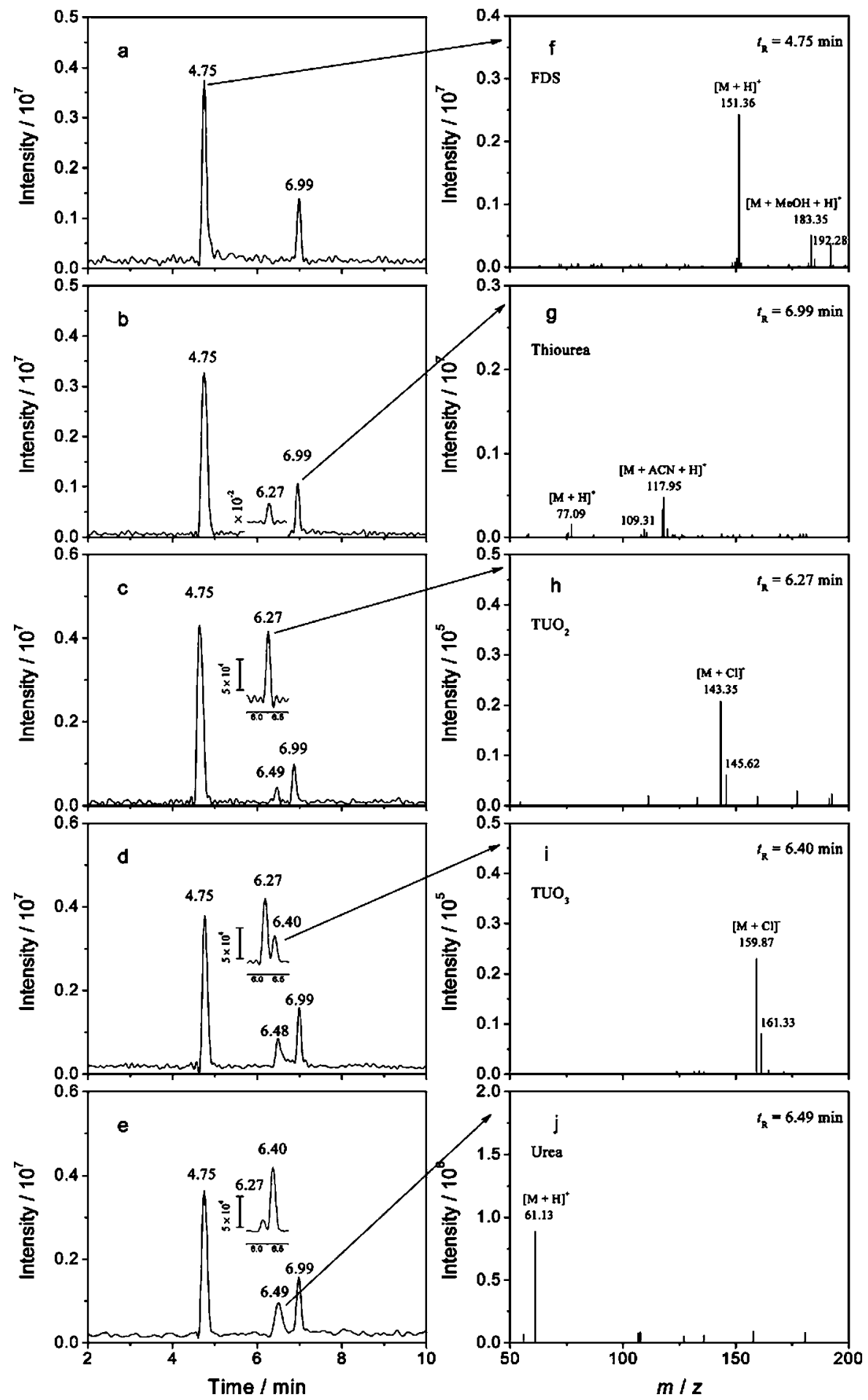

Figure 7. $(\mathrm{a}-\mathrm{e}) \mathrm{TIC}$ chromatograms of electrolysis products in $0.5 \mathrm{M} \mathrm{HCl}$ solution at various potentials and (f-j) mass spectra of the corresponding eluted components: (a,f) 0.65 , (b,g) 1.0 , (c,h) 1.25 , (d,i) 1.50 , and (e,j) $1.75 \mathrm{~V} . T=20^{\circ} \mathrm{C}$.

$\mathrm{M} \mathrm{HClO}_{4}$ solution in the potential range between -0.1 and 0.6 $\mathrm{V}$, except that the peak currents are somewhat larger. However, when the anodic switching potential is extended to $1.45 \mathrm{~V}$, quite different behavior is observed. As presented in Figure 6d, in the absence of thiourea, adsorption and desorption are dramatically enhanced when the potential is increased above ca. 1.10 $\mathrm{V}$, as indicated by the much larger current density. The effects of chloride adsorption are largely impervious to the presence of $1 \mathrm{mM}$ thiourea, and the current comes almost entirely from the faradaic adsorption reaction of chloride at potentials above $1.2 \mathrm{~V}$. This result indicates that the adsorption of chloride cannot be ignored, and it might play a role in the oscillatory mechanism.
To determine the possible products at various electrode potentials, we performed electrolysis-HPLC-MS experiments. The electrolysis was performed in $0.5 \mathrm{M} \mathrm{HCl}$ solution from 0.5 to $2.0 \mathrm{~V}$ for $8 \mathrm{~h}$. The products were then separated by HPLC, and both mass spectrometric and UV signals were recorded. Figure 7 shows typical TIC (total ion current) chromatograms obtained from a solution containing $10 \mathrm{mM}$ thiourea. As shown in Figure $7 \mathrm{a}$, when the potential is held at $0.65 \mathrm{~V}$, in addition to the residual thiourea $\left[\left(\mathrm{H}_{2} \mathrm{~N}\right)_{2} \mathrm{CS}, \mathrm{TU}\right]$ that appears at a retention time, $t_{\mathrm{R}}$, of $6.99 \mathrm{~min}$, the major product is obtained at $t_{\mathrm{R}}=4.61 \mathrm{~min}$. Comparison with reference mass spectra suggests that this peak corresponds to $\mathrm{c}, \mathrm{c}^{\prime}$-dithiodiformamidinium 

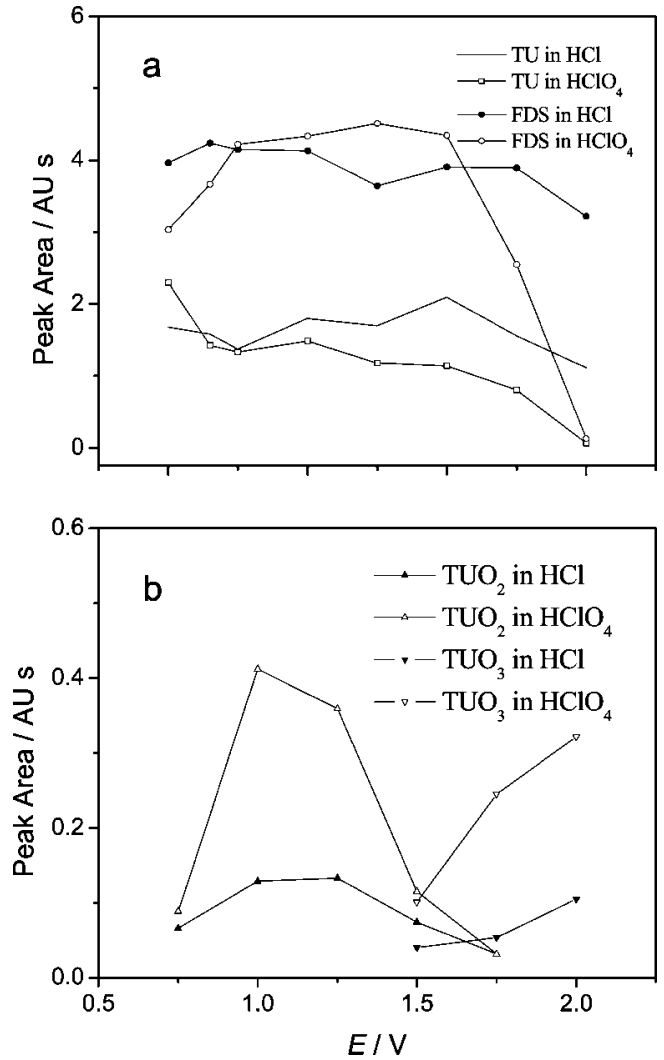

Figure 8. HPLC peak areas corresponding to (a) TU and FDS and (b) $\mathrm{TUO}_{2}$ and $\mathrm{TUO}_{3}$ in $\mathrm{HCl}$ and $\mathrm{HClO}_{4}$ solutions at potentials from 0.50 to 2.0 V. $T=20^{\circ} \mathrm{C}$.

$\left(\left[\left(\mathrm{NH}_{2}\right)_{2} \mathrm{CSSC}\left(\mathrm{NH}_{2}\right)_{2}\right]^{2+}\right.$, FDS), in agreement with the $\mathrm{CV}$ results and previous suggestions. ${ }^{23,24}$ As the potential increases, the electrochemical reaction rate, i.e., the oxidation current, increases, leading to a decrease in thiourea concentration as the concentration of FDS increases. Above ca. $0.75 \mathrm{~V}$, thiourea can be further oxidized, yielding various products. When the potential is kept at $1.0 \mathrm{~V}$, both thiourea and FDS can be detected in positive-ion mode. Although it is not generally recommended to use negative-ion mode with a strongly acidic mobile phase, formamidine sulfnic acid $\left[\left(\mathrm{H}_{2} \mathrm{~N}\right)_{2} \mathrm{CSO}_{2}, \mathrm{TUO}_{2}\right]$ can still be detected by such an unconventional approach. As shown in Figure $7 \mathrm{~b}, \mathrm{TUO}_{2}$ elutes at $t_{\mathrm{R}}=6.27 \mathrm{~min}$, and it appears in the mass spectrum at a mass-to-charge ratio of 143.35 (bound to $\mathrm{Cl}^{-}$). At a potential of $1.25 \mathrm{~V}$, another product with mass ca. 60 and $t_{\mathrm{R}}=6.49 \mathrm{~min}$ appears (Figure $7 \mathrm{c}$ ), which we identify as urea. Formamidine sulfonic acid $\left[\left(\mathrm{H}_{2} \mathrm{~N}\right)_{2} \mathrm{CSO}_{3}, \mathrm{TUO}_{3}\right]$ is formed when the potential is increased to ca. $1.50 \mathrm{~V}\left(t_{\mathrm{R}}=6.38\right.$, see Figure 7d). As depicted in Figure 7e, if the potential is increased still further, the concentration of $\mathrm{TUO}_{2}$ decreases, and the concentration of $\mathrm{TUO}_{3}$ increases. Addition of $\mathrm{BaCl}_{2}$ to the product solutions results in formation of a white precipitate at potentials above ca. $1.50 \mathrm{~V}$, suggesting that $\mathrm{SO}_{4}{ }^{2-}$ can be formed at these potentials.

To assess the effect of chloride on the overall process of thiourea oxidation and its contribution to the mechanism of oscillation, we used HPLC with a MWD UV spectrometer as detector to analyze the products in $\mathrm{HCl}$ and $\mathrm{HClO}_{4}$ solutions. For ease of comparison, the electrolysis time was limited to $2.5 \mathrm{~h}$. All retention times reported here are $0.14 \mathrm{~min}$ shorter than those found with MS because of the time delay caused by the pathway between the UV detector and the ion source. Figure 8 presents the peak areas of each effluent in the $\mathrm{HCl}$ and $\mathrm{HClO}_{4}$ solutions. At potentials below $0.75 \mathrm{~V}$, FDS production and thiourea consumption are both greater in $0.5 \mathrm{M} \mathrm{HCl}$ than in $0.5 \mathrm{M} \mathrm{HClO}_{4}$. Between 0.75 and $1.50 \mathrm{~V}$, the concentrations of thiourea, FDS, and $\mathrm{TUO}_{2}$ are higher in $\mathrm{HClO}_{4}$ solution. Further increasing the potential leads to a dramatic decrease in thiourea and FDS in $\mathrm{HClO}_{4}$, indicating that the oxidation reaction in $\mathrm{HClO}_{4}$ solution is much faster. When the potential is kept at $2.0 \mathrm{~V}$, only small amounts of thiourea, $\mathrm{FDS}, \mathrm{TUO}_{2}$, and $\mathrm{TUO}_{3}$ can be detected, suggesting that substances with low or no UV absorption such as urea, $\mathrm{SO}_{4}{ }^{2-}$, or even $\mathrm{N}_{2}$ or $\mathrm{CO}_{2}$ are formed. In $0.5 \mathrm{M} \mathrm{HCl}$, the amounts of residual thiourea, FDS, $\mathrm{TUO}_{2}$, and $\mathrm{TUO}_{3}$ are much higher. As indicated in the cyclic voltammograms (Figure 6d), the adsorption and desorption of chloride are significant at these potentials, which might inhibit the adsorption and desorption of water. As an oxygen-transfer reaction, the further oxidation of thiourea requires generation of adsorbed hydroxyl radicals $\left({ }^{\circ} \mathrm{OH}_{\mathrm{ads}}\right)$ during concomitant formation of surface oxides at the electrode surface. ${ }^{27}$ The competing adsorption of chloride might decrease the thiourea oxidation rate and contribute to the oscillatory mechanism.

In oscillation region A, the main product is FDS, according to the above results and earlier studies, ${ }^{23,24}$ and the most likely reactions are

$$
\begin{gathered}
\left(\mathrm{H}_{2} \mathrm{~N}\right)_{2} \mathrm{CS} \rightarrow\left[\left(\mathrm{H}_{2} \mathrm{~N}\right)_{2} \mathrm{CS}^{\bullet}\right]^{+}+\mathrm{e}^{-} \\
2\left[\left(\mathrm{H}_{2} \mathrm{~N}\right)_{2} \mathrm{CS}^{\bullet}\right]^{+} \leftrightarrow\left[\left(\mathrm{H}_{2} \mathrm{~N}\right)_{2} \mathrm{CSSC}\left(\mathrm{HN}_{2}\right)_{2}\right]^{2+}
\end{gathered}
$$

Judging from the potentials, $\mathrm{TUO}_{2}$ and urea can also form in this region. These processes can be described by the reactions ${ }^{24}$

$$
\begin{gathered}
{\left[\left(\mathrm{H}_{2} \mathrm{~N}\right)_{2} \mathrm{CS}^{\bullet}\right]^{+}+\mathrm{H}_{2} \mathrm{O} \rightarrow\left[\left(\mathrm{H}_{2} \mathrm{~N}\right)_{2} \mathrm{CSOH}_{2}\right]^{+}} \\
{\left[\left(\mathrm{H}_{2} \mathrm{~N}\right)_{2} \mathrm{CSOH}_{2}\right]^{+} \rightarrow\left[\left(\mathrm{H}_{2} \mathrm{~N}\right)_{2} \mathrm{CSOH}_{2}\right]^{2+}+\mathrm{e}^{-}} \\
{\left[\left(\mathrm{H}_{2} \mathrm{~N}\right)_{2} \mathrm{CSOH}_{2}\right]^{2+} \rightarrow\left(\mathrm{H}_{2} \mathrm{~N}\right)_{2} \mathrm{CSO}+2 \mathrm{H}^{+}} \\
\left(\mathrm{H}_{2} \mathrm{~N}\right)_{2} \mathrm{CSO}+\mathrm{H}_{2} \mathrm{O} \rightarrow\left(\mathrm{H}_{2} \mathrm{~N}\right)_{2} \mathrm{CSO}_{2}+2 \mathrm{H}^{+}+2 \mathrm{e}^{-} \\
{\left[\left(\mathrm{H}_{2} \mathrm{~N}\right)_{2} \mathrm{CSOH}_{2}\right]^{2+} \rightarrow \mathrm{S}+\left(\mathrm{H}_{2} \mathrm{~N}\right)_{2} \mathrm{CO}+2 \mathrm{H}^{+}}
\end{gathered}
$$

At high concentrations of thiourea, diprotonated sulfenic acid, $\left[\left(\mathrm{H}_{2} \mathrm{~N}\right)_{2} \mathrm{CSOH}_{2}\right]^{2+}$, can react with thiourea, yielding FDS

$$
\begin{aligned}
{\left[\left(\mathrm{H}_{2} \mathrm{~N}\right)_{2} \mathrm{CSOH}_{2}\right]^{2+}+} & \left(\mathrm{NH}_{2}\right)_{2} \mathrm{CS} \rightarrow \\
& {\left[\left(\mathrm{NH}_{2}\right)_{2} \mathrm{CSSC}\left(\mathrm{NH}_{2}\right)_{2}\right]^{2+}+\mathrm{H}_{2} \mathrm{O} }
\end{aligned}
$$

In the potential region of oscillation $\mathrm{B}, \mathrm{TUO}_{2}$ can be further oxidized to $\mathrm{TUO}_{3}$. At these potentials, both $\mathrm{TUO}_{3}$ and urea can be completely oxidized to nitrogen, carbon dioxide, and sulfate. ${ }^{23}$

$$
\begin{gathered}
\left(\mathrm{NH}_{2}\right)_{2} \mathrm{CSO}_{2}+\mathrm{H}_{2} \mathrm{O} \rightarrow\left(\mathrm{NH}_{2}\right)_{2} \mathrm{CSO}_{3}+2 \mathrm{H}^{+}+2 \mathrm{e}^{-}(\mathrm{R} 9) \\
\left(\mathrm{NH}_{2}\right)_{2} \mathrm{CSO}_{3}+3 \mathrm{H}_{2} \mathrm{O} \rightarrow \mathrm{SO}_{4}{ }^{2-}+\mathrm{CO}_{2}+\mathrm{N}_{2}+10 \mathrm{H}^{+}+8 \mathrm{e}^{-}
\end{gathered}
$$

Clearly, reactions R6, R9, and R10 cannot be elementary reactions, as electron-transfer theory ${ }^{28}$ predicts that electrons can only be transferred one at a time. As oxygen is transferred from water to product molecules, the adsorption and desorption of water might play an important role in these oxidation processes. ${ }^{27}$

$$
\mathrm{H}_{2} \mathrm{O} \rightarrow \cdot \mathrm{OH}+\mathrm{H}^{+}+\mathrm{e}^{-}
$$

The adsorption of hydroxyl radical is strongly suppressed by the adsorption of chloride ions. We conclude that further oxidation of thiourea can occur through the indirect interaction of adsorbed residues and hydroxyl radicals. As revealed by the 
$\mathrm{CV}$ and HPLC experiments, the adsorption of chloride ion has a significant influence on the oxidation of thiourea in oscillation B

$$
\mathrm{Cl}^{-} \rightarrow \mathrm{Cl}^{\bullet}+\mathrm{e}^{-}
$$

The strong competing adsorption of chloride might poison the electrode surface and inhibit the oxidation of thiourea. As complex oscillations can be observed only in the presence of specifically adsorbed anion $\mathrm{Cl}^{-}$, reaction $\mathrm{R} 12$ might play an important role in the oscillatory mechanism, which we plan to study in future work. The competing absorption and desorption of species, including sulfur-containing intermediates, water, and chloride, causes the system to display rich nonlinear dynamics such as periodic doubling oscillations, ${ }^{25}$ quasiperiodic oscillations, and mixed-mode oscillations.

Acknowledgment. This work was supported by Grant CHE0615507 from the U.S. National Science Foundation, Grant 20573134 from the National Science Foundation of China, and Grant 20050290512 from the Ministry of Chinese Education. Q.G. is grateful for the financial support of the visiting program to Brandeis University from the Chinese Scholarship Council.

\section{References and Notes}

(1) Hilborn, R. C. Chaos and Nonlinear Dynamics: An Introduction for Scientists and Engineers, 2nd ed.; Oxford University Press: Oxford, U.K., 1994.

(2) Nicolis, G. Introduction to Nonlinear Science; Cambridge University Press: Cambridge, U.K., 1995.

(3) Nicolis, G.; Prigogine, I. Self-Organization in Nonequilibrium Systems; Wiley: New York, 1977.

(4) Schuster, H. G. Deterministic Chaos: An Introduction, 2nd ed.; VCH: Weinheim, Germany, 1988.
(5) Haken, H. Synergetics; Springer: Berlin, 1977.

(6) Lindsay, W. C. Synchronization Systems in Communication and Control; Prentice-Hall: Upper Saddle River, NJ, 1972.

(7) Aoki, K. Nonlinear Dynamics and Chaos in Semiconductors; IOP Publishing: Bristol, U.K., 2000.

(8) Glass, L.; Mackey, M. C. From Clocks to Chaos: The Rhythms of Life; Princeton University Press: Princeton, NJ, 1988.

(9) Schmitz, R. A.; Graziani, K. R.; Hudson, J. L. J. Chem. Phys. 1977, 67,3040

(10) Kuramoto, Y. Chemical Oscillations, Waves and Turbulence; Spinger-Verlag: Berlin, 1984.

(11) Scott, S. K. Chemical Chaos; Clarendon Press: Oxford, U.K., 1991.

(12) Strasser, P.; Eiswirth, M.; Koper, M. T. M. J. Electroanal. Chem. 1999, $478,50$.

(13) Hudson, J. L.; Tsotsis, T. T. Chem. Eng. Sci. 1994, 49, 1493.

(14) Krischer, K., Alkire, R. C., Kolb D. M. Eds. Advances in Electrochemical Science and Engineering; Wiley-VCH: New York, 2003; Vol. 8.

(15) Landau, L. D.; Dokl, C. R. Acad. Sci. USSR 1944, 44, 311.

(16) Ruelle, D.; Takens, F. Commun. Math. Phys. 1971, $20,167$.

(17) Newhouse, S. E.; Ruelle, D.; Takens, F. Commun. Math. Phys. 1978, 64,35 .

(18) Swinney, H. L.; Gollub, J. P. Phys. Today 1978, 31, 8.

(19) Li, T. Y.; Yorke, J. A. Am. Math. Monthly 1975, 82, 985.

(20) Grebogi, C.; Ott, E.; Yorke, J. A. Phys. Rev. Lett. 1983, 51, 339.

(21) Libchaber, A.; Fauve, S.; Laroche, C. Physica D 1983, 7, 73. 303.

(22) Martin, S.; Leber, H.; Martienssen, W. Phys. Rev. Lett. 1984, 53,

(23) Bolzán, A. E.; Wakenge, I. B.; Salvarezza, R. C.; Arvia, A. J. J. Electroanal. Chem. 1999, 475, 1181.

(24) Kirchnerová, J.; Purdy, W. C. Anal. Chim. Acta 1981, 123, 83.

(25) Xu, L.; Gao, Q.; Feng, J.; Wang, J. Chem. Phys. Lett. 2004, 397, 265.

(26) Bard, A. J.; Faulkner, L. R. Electrochemical Methods: Fundamentals and Applications, 2nd ed.; Wiley: New York, 2001.

(27) Vitt, J. E.; Johnson, D. C. J. Electrochem. Soc. 1992, 139, 774.

(28) Libby, W. F. Ann. Rev. Phys. Chem. 1977, 28, 105.

\section{JP802002K}

